\title{
A cost-effectiveness analysis of a telephone-linked care intervention for individuals with Type 2 diabetes
}

LG Gordon PhD ${ }^{1}$, D Bird PhD ${ }^{2,3}$, B Oldenburg $\mathrm{PhD}^{2}, \mathrm{RH}$ Friedman $\mathrm{PhD}^{4}, \mathrm{AW}$ Russell PhD ${ }^{5,6}$, PA Scuffham $\mathrm{PhD}^{1}$.

1. Centre for Applied Health Economics, Griffith Health Institute, Griffith University, University Dr, Meadowbrook, Queensland, Australia

2. School of Public Health and Preventive Medicine, Monash University, Queensland Australia

3. School of Nursing, Queensland University of Technology, Australia

4. Medical Information Systems Unit, Department of Medicine, Boston University School of Medicine, Boston, Massachusetts, USA

5. Department of Diabetes and Endocrinology, Princess Alexandra Hospital, Woollongabba, Queensland, Australia

6. School of Medicine, The University of Queensland, Brisbane, Queensland, Australia

Correspondence to: Louisa Gordon, Centre for Applied Health Economics, Griffith Health Institute, Griffith University, University Dr, Meadowbrook Queensland 4131, AUSTRALIA Ph:61-7-3382 1320 Fx:61-733821160 Louisa.Gordon@griffith.edu.au

Funding Source: The study was funded by a NHMRC Project Grant (ID 443214). 
Conflicts of Interest: Professor Friedman has stock ownership and a consulting agreement with Infomedics, the company that owns commercial rights to the TLC technology used in the computerized intervention. He is also a member of its Board of Directors. The remaining authors declare no conflicts of interest. 


\section{Abstract}

Aim: To assess the cost-effectiveness of an automated telephone-linked care intervention, Australian TLC Diabetes, delivered over 6 months to patients with established Type 2 diabetes mellitus and high glycated haemoglobin level, compared to usual care.

Methods: A Markov model was designed to synthesize data from a randomized controlled trial of TLC Diabetes $(n=120)$ and other published evidence. The 5-year model consisted of three health states related to glycaemic control: 'sub-optimal' $\mathrm{HbA}_{1 \mathrm{c}} \geq 58 \mathrm{mmol} / \mathrm{mol}(7.5 \%)$; 'average' $\geq 48-57 \mathrm{mmol} / \mathrm{mol}$ (6.5- 7.4\%) and 'optimal' $<48 \mathrm{mmol} / \mathrm{mol}(6.5 \%)$ and a fourth state 'all-cause death'. Key outcomes of the model include discounted health system costs and quality-adjusted life years (QALYS) using SF-6D utility weights. Univariate and probabilistic sensitivity analyses were undertaken.

Results: Annual medication costs for the intervention group were lower than usual care [Intervention: $£ 1076$ (95\%Cl: $£ 947, £ 1206)$ versus usual care $£ 1271$ (95\%Cl: $£ 1115, £ 1428,) p=0.052]$. The estimated mean cost for intervention group participants over five years, including the intervention cost, was $£ 17,152$ versus $£ 17,835$ for the usual care group. The corresponding mean QALYs were 3.381 (SD 0.40) for the intervention group and 3.377 (SD 0.41) for the usual care group. Results were sensitive to the model duration, utility values and medication costs. Conclusion: The Australian TLC Diabetes intervention was a low-cost investment for individuals with established diabetes and may result in medication cost-savings to the health system. Although QALYs were similar between groups, other benefits arising from the intervention should also be considered when determining the overall value of this strategy. 
Key words: tele-health, cost-effectiveness analysis, Type 2 diabetes

\section{Introduction}

With the rapidly rising prevalence of Type 2 diabetes worldwide [3], the use of information and communication technology could be an effective way of delivering diabetes self-management programs to large numbers of people with

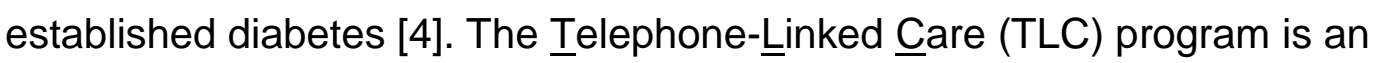
automated and interactive telephone system designed to simulate natural patient and health professional encounters and to complement standard medical care [5-7]. This technology has been previously found to be effective in screening for specific health conditions, promoting self-care behaviours and for improving health care outcomes for a range of chronic diseases [8-10] .

A recent Australian randomized controlled trial evaluated a TLC program targeting Type 2 diabetes management, the Australian TLC Diabetes [4, 11]. The primary outcomes of the trial were glycated haemoglobin $\left(\mathrm{HbA}_{1 \mathrm{c}}\right)$ and health-related quality of life (HRQoL) [4]. Following a 6-month intervention period, TLC-Diabetes patients compared to usual care controls showed significantly greater improvements in $\mathrm{HbA}_{1 \mathrm{c}}$ (mean reduction $15 \mathrm{mmol} / \mathrm{mol}$ or $0.8 \%, \mathrm{p}=0.002$ ) and quality of life mental health scores (SF-36 Mental Component Score difference $=3.0, p=0.007$.) There are potentially large benefits in the longer term if these benefits are enduring. For example, it has been reported that a decrease of $13 \mathrm{mmol} / \mathrm{mol}(1 \%)$ in $\mathrm{HbA}_{1 \mathrm{c}}$ is linked to $21 \%$ fewer deaths, $14 \%$ fewer non-fatal myocardial infarctions and a reduction in microvascular complications (retinopathy, nephropathy) by $37 \%$ [12]. 
Population-level interventions that successfully generate patient benefits will also help to stem the rising economic burden of diabetes care faced by health systems. Cost-effectiveness analysis is a useful technique that presents both the costs and health benefits of alternative population-level strategies for delivering health services and is invaluable for health policy makers and reimbursement agencies. The purpose of this study was to assess the relative costs and health benefits of the Australian TLC Diabetes program compared to usual care, using information collected as part of an Australian randomized control trial, and therefore assess the value for money of the intervention $[4,11]$.

\section{Methods}

\section{Overview}

Cost-effectiveness was assessed over a 5-year time period, using patient-level data from the Australian TLC Diabetes program wherever possible and supplemented with data for the post-trial period from a brief literature review. Details of the original protocol for the clinical and economic methods are provided in a previous publication [11]. Briefly, participants had a diagnosis of Type 2 diabetes of $\geq 3$ months duration, were aged 18-70 years, had access to a telephone, had an $\mathrm{HbA}_{1 \mathrm{c}}$ level $\geq 58$ $\mathrm{mmol} / \mathrm{mol}(7.5 \%)$ and, if medicated, were on stable diabetes pharmacotherapy. Exclusion criteria included: diagnosis of a condition with likely poor prognosis within one year; diagnosis with dementia or a psychiatric co-morbidity; pregnant, lactating, or planning to become pregnant within the next 12 months; currently enrolled in another intervention trial; or have undergone bariatric surgery in the past two years. The study randomized 120 patients to either the Australian TLC Diabetes 
intervention or a usual care arm. The TLC Diabetes intervention was 24 weeks in duration. It consisted of educational advice and feedback on diabetes selfmanagement provided to patients during weekly telephone calls to TLC Diabetes which promoted blood glucose monitoring, medication taking, healthy eating and regular physical activity. Patients received a TLC Diabetes kit containing a handbook, an ACCU-CHEK@ Advantage blood glucose meter, a box of test strips, a cell phone and a Bluetooth ${ }^{\mathrm{TM}}$ device that uploaded their blood glucose readings from their ACCU-CHEK® meter to the TLC Diabetes computer server by transmitting them wirelessly using the cell phone. Advice was tailored to patient needs, for example, feedback on blood glucose testing frequency was based on individualized weekly frequency targets set prior to the intervention $[4,11]$. Assessment times were at baseline, 6 and 12 months. Baseline characteristics of the study participants are provided in Appendix A.

\section{Markov Model}

We constructed a health state transition Markov Model to synthesize data from the Australian TLC Diabetes project and other published evidence, using TreeAge Pro 2011 (TreeAge Software Inc, Williamstown, MA, USA). The model consisted of three health states related to glycemic control from a starting point using the trial eligibility level of $\mathrm{HbA}_{1 \mathrm{c}} \geq 58 \mathrm{mmol} / \mathrm{mol}(7.5 \%)$ : 'sub-optimal control' [ $\geq 58 \mathrm{mmol} / \mathrm{mol}(7.5 \%)$

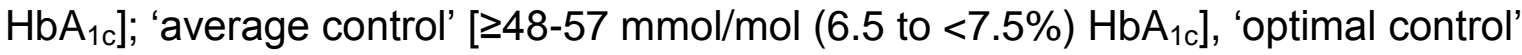
[ $<48 \mathrm{mmol} / \mathrm{mol}(6.5 \%)]$, and a fourth health state of 'all-cause death'. The health state categories were based on evidence that a $1 \%$ difference in $\mathrm{HbA}_{1 \mathrm{c}}$ levels is associated with clinically significant differences in glycemic control and risk of diabetes complications [12]. Individuals can move between these mutually exclusive 
health states, once every six months, or remain in the same state. In an additional analysis, these categories were repeated for the alternative $\mathrm{HbA}_{1 \mathrm{c}}$ cut-offs of $>64$ $\mathrm{mmol} / \mathrm{mol}(8.0 \%), 53-64 \mathrm{mmol} / \mathrm{mol}(7.0-8.0 \%)$ and $<53 \mathrm{mmol} / \mathrm{mol}(7.0 \%)$ to assess whether these categories influenced the results. Key outcomes of the model included costs and the generic outcome 'quality-adjusted life years' (QALYS). Guidelines for best-practice procedures for economic modelling were adhered to during our study [13].

\section{Data Inputs and Sources}

Resource Use and Costs. We documented itemized labour costs and equipment costs (i.e., Bluetooth ${ }^{\mathrm{TM}}$ devices, cell phones and computer) that were part of the program delivery system. Healthcare costs included general practitioner and specialist visits, allied health encounters, hospitalizations and all medication use. Due to the very high volume of individual medicines used, medications used were collated into general therapeutic drug classes and a mean cost for these general classes was used, based on a prior diabetes cost analysis in Australia [14]. Hospitalization data were obtained from Queensland Health Admitted Patients Data Collection and other healthcare utilization was based on participants' self-reports of utilization during the prior six months that were collected at the three assessment time points (zero, six and 12 months). Resources were valued using national price schedules [15-17]).

Health Utilities. To determine health utilities, we used a 12-item subscale of the SF36 (the SF-6D) [18] which is an acceptable preference-based utility tool for use in economic evaluations to generate the outcome 'quality-adjusted life years' (QALYs). 
The UK population scoring algorithm was applied to produce a score between 0 and 1 , with 1 representing the best and 0 worst possible health status for each study participant. The analyses of SF-6D scores were not found to be minimally different across time and intervention group (Table 1) or across $\mathrm{HbA}_{1 \mathrm{c}}$ health state categories. This outcome was inconsistent with what is known about health utilities by glucose control categories, namely, that patients with higher $\mathrm{HbA}_{1 \mathrm{c}}$ levels report lower utilities [19]. Therefore, we used the average utility value for the whole study group at the 12 month follow-up (0.726) for the 'sub-optimal control' category and added an increment of 0.029 for 'average control' and 0.058 for 'optimal control' categories. These increments were calculated based on SF-6D scores reported in Australian patients with impaired glucose tolerance and Type 2 diabetes with similar age and BMI [19].

Transition probabilities. In each 6-month cycle after baseline, a proportion of individuals will either continue to live with sub-optimal glycemic control or improve to average or optimal control, and all other combinations. The transition probabilities are taken directly from the $\mathrm{HbA}_{1 \mathrm{c}}$ values collected during the 12 month study period and stratified by the intervention and control groups from baseline to 6 months and from 6 to 12 months (Table 2). Thereafter, an assumption was made to maintain the same transition probabilities as those during the maintenance phase (6 to 12 months) at a constant rate out to 5 years.

Relative risk of mortality. We used data from the Australian 'AusDiab' study which reports on the excess mortality attributed to elevated $\mathrm{HbA}_{1 \mathrm{c}}$ levels over a 7-year follow-up [20] (Table 2). The relative risk of all-cause death in individuals with 
established Type 2 diabetes was $2.3(95 \% \mathrm{Cl}: 1.6,3.2)$ with $\mathrm{HbA}_{1 \mathrm{c}}>48 \mathrm{mmol} / \mathrm{mol}$ (6.5\%), compared to individuals without diabetes. This relative risk was applied to background mortality rates based on Australian Bureau of Statistics age-dependent mortality tables for patients entering the 'optimal control' health state. Evidence suggests that the relative risk for excess mortality increases in a linear pattern as $\mathrm{HbA}_{1 \mathrm{c}}$ levels rise [21] and therefore we linearly interpolated relative risks in higher $\mathrm{HbA}_{1 \mathrm{c}}$ categories to align with the model health states.

\section{Analyses}

All costs (Table 2) were inflated to 2011 dollars using the Australian Consumer Price Index and presented in pounds (AUD $1=£ 0.657,2011)$. Total healthcare costs across the two groups and by broad type of healthcare utilization were compared using non-parametric bootstrap statistics with replacement and the bias-corrected approach [22]. Differences across study groups were tested with the Wald test and results were significant at $p<0.05$. Mean SF-6D scores across the time points and groups were assessed by repeated-measures analysis of variance. The 5-year mean costs and QALYs were generated using an expected value (mean per person) analysis which aggregates the probabilities and values assigned to the different health states. Costs and benefits were discounted at $5 \%$ per year to adjust to present values. The incremental cost-effectiveness ratio was calculated by the difference in costs divided by the difference in QALYs for the two groups.

One-way sensitivity analyses were undertaken where each parameter was varied through a range of plausible values (Table 2) and changes to the base results were observed. Starting age and model duration were varied and all other model 
parameters were tested between high and low values using the $95 \%$ confidence intervals where available, values reported in the literature, or $\pm 30 \%$ (Table 1 ). Intervention costs that incorporate equipment were varied $\pm 30 \%$. Higher equipment costs could be possible, for example, potentially covering a shorter life-span in cell phones or Bluetooth devices. A probabilistic sensitivity analysis was also performed by re-sampling 5000 times at random from assigned probability distributions for each parameter. This is similar to multivariate sensitivity analysis and addresses the uncertainty of data estimates simultaneously. Log-normal distributions were assigned to relative risks, gamma distributions for costs and beta distributions were used for probabilities and utility scores.

\section{Scenario analyses}

To assess the uncertainty in the sustainability of the intervention effect, we also varied the transitions between $\mathrm{HbA}_{1 \mathrm{c}}$ health states after the trial period ended. Two scenarios were tested which are labelled the 'optimistic' and 'pessimistic' scenarios. The optimistic scenario applied 0-6 month transition probabilities in the sub-optimal state across all cycles up to 5 years and the pessimistic scenario assumed higher probabilities for unfavourable transitions for remaining in the average state or transitioning from average to the sub-optimal state (Table 2). A third scenario simply averaged the 0-6 month and 6-12 month transitions and extrapolated these for the 5year duration. The probability sensitivity analysis was repeated to account for the optimistic and pessimistic scenarios.

\section{Results}

SF-6D scores were similar at baseline across the intervention 0.728 (SD 0.12) and usual care 0.727 (SD 0.14) groups. By 12 months, the intervention group had a 
slightly higher mean SF-6D score $0.736(0.14)$ than usual care $0.716(0.13)$ but the difference was not statistically significant (Table 1). Annual mean costs were similar for both groups for GP and specialist visits, allied health and hospitalization and no statistically significant differences were shown (Table 1). However, medication use for the intervention group was lower than usual care's use with borderline significance [Intervention: $£ 1076(95 \% \mathrm{Cl}$ : $947, £ 1206)$ versus usual care $£ 1271$ (95\%Cl: $£ 1115, £ 1428,) p=0.052]$. Lower medication costs over 12 months in the intervention group were attributed to a lower proportion of participants in the intervention group receiving medications across the entire range of medication categories, including lower use of lipid-modifying agents, anti-thrombotics and 'other' medicines (with the most common being analgesics, anti-inflammatory agents, and thyroid therapies). Further details of medication use are provided in the Supplementary File. Consequently, the group-specific mean values were used in the economic model for medication use. The total intervention cost was £533per person, mostly made up of the mobile phone and blue tooth devices (Table 2).

In the base case, the predicted mean cost for the TLC intervention group over five years, including the costs for the intervention, was $£ 17,152$ versus $£ 17,835$ for the usual care group (Table 3 ), creating a cost-saving of £683mean per person. The corresponding mean QALYs were 3.381 for the intervention group and 3.377 for the usual care group. The difference in QALYs (0.004) is not considered meaningful.

In one-way sensitivity analyses, the results were sensitive to the estimates for model duration, utilities and medication costs (Table 3). Unlike the other estimates, the choice of utility values for the optimal and sub-optimal $\mathrm{HbA}_{1 \mathrm{c}}$ health states changed 
the base findings so that there were fewer QALYs in the intervention group. High medication costs for the intervention group or lower medication costs for the usual care group lead to higher mean costs and very high incremental cost per QALY gained ratios. The results of the probabilistic sensitivity analyses indicated that the likelihood of the intervention being cost-effective was $55.4 \%$ at a willingness-to-pay threshold of $\$ 50,000(£ 33,000)$ per QALY gained (Figure 1). Changing the pattern of transition probabilities between the $\mathrm{HbA}_{1 \mathrm{c}}$ health states did not materially alter the base findings that showed higher QALYs and lower costs than usual care. Under the optimistic scenario, where a larger proportion of intervention participants maintained or improved their $\mathrm{HbA}_{1 \mathrm{c}}$ levels, the probability of cost-effectiveness was $59.4 \%$ compared to $53.8 \%$ for the pessimistic scenario.

\section{Discussion}

The results show that the estimated healthcare costs were, on average, lower for the intervention group compared to the usual care group. However, health status as reported by the SF-6D was similar for both groups. The intervention costs were offset by lower medication use but the health utilities and mortality risks were similar across groups. Furthermore, the likelihood of the intervention being cost-effective was marginal at $55 \%$ according to acceptable cost-effectiveness thresholds.

Previous reviews have examined studies of self-management programs in community settings, focusing on lifestyle behaviour change, skills development and glucose self-monitoring among adults with Type 2 diabetes [1, 2]. These showed pooled glycated haemoglobin levels improving by $0.5 \%(95 \% \mathrm{Cl}: 0.1 \%, 1.1 \%)$ at 12 
months in two home-based studies and improving by $0.26 \%$ at greater than 4 months in 31 studies across all settings [1, 2]. Compared with the findings of these studies, the glycated haemoglobin results of our study are comparable.

A balanced view of the intervention benefits should also incorporate other performance indicators of patient benefits as well. These include (1) improvements in the mental health of patients (as shown in the mental health component of the SF36), (2) increased diabetes self-care activities by patients, and (3) improved access to diabetes resources and self-management support for patients living in rural and remote areas in Australia. The monitoring of blood glucose levels coupled with alerts to the TLC Diabetes coordinator for low (hypoglycaemic) and high (hyperglycaemic) events may lead to earlier intervention by clinicians than for diabetes patients who did not receive TLC Diabetes. The frequency and duration of contact by participants with the program were impressive with the majority of calls to the system completed [4]. The cost-savings for medications are encouraging, while at the same time the intervention was relatively low cost in relation to total healthcare costs for diabetes, an estimated $£ 533$ versus approximately $£ 17,000$ over 5 years. Furthermore, the ongoing variable costs are relatively small. Since the TLC system can support many more than the 60 enrolees in the evaluation study at any one time, its scalability to a large number of users in the future is very feasible and cost-effective. For example, delivery to 1000 patients would lower the cost per patient to $£ 447$ and delivery to 10,000 patients would cost only £301 per patient (Table 2).

While there is accumulating evidence showing the potential clinical benefits of mobile phone tele-health solutions for blood glucose monitoring and self-management in 
patients with diabetes [23], only a few have assessed their economic value [23-26]. Only one large multi-site UK study by Henderson et al (2013) has comprehensively assessed both the relative costs and QALY outcomes [25]. Matching our findings, the QALY gain between the telehealth intervention and usual care was similar but costs were found to be higher for the intervention group ( $£ 1500-£ 2000$ depending on site) and overall the findings were not considered cost-effective. The authors found that if returns to scale could be made and the program was at increased capacity, the probability of the intervention being cost-effective at $£ 30,000$ per QALY was increased to $61 \%$. Despite there being many differences between our study and Henderson's in the intervention type, patient profile, scope of the costs included and modelling approach, this promise of better cost-effectiveness with scalability was similar to our finding.

This study has a number of limitations. Participants from the Australian TLCDiabetes trial were carefully selected, and may not be representative of the wider population of patients with diabetes. Our cost-effectiveness model simplifies what is a complex disease for which optimal treatment depends on a variety of factors. For example, it is recommended that general practitioners individualize $\mathrm{HbA}_{1 \mathrm{c}}$ targets to guide treatment and take into account the presence of disease comorbidities, which are common, patient motivation and harm minimization [27, 28]. The cut-offs chosen for the categories of $\mathrm{HbA}_{1 \mathrm{c}}$ used in our model conform to generally accepted standards for defining improved or worsened diabetes status [27]. When these cutoffs were raised by $18 \mathrm{mmol} / \mathrm{mol}(0.5 \%)$ in each category and the analyses re-run, we found this did not materially alter the study findings. Our population-based model necessarily uses averaged costs and outcomes in a 'steady-state' and therefore 
loses the precision and complexities of individual patient management. However, our comprehensive sensitivity analyses address this uncertainty and any potential bias in the model parameters chosen.

Systematic reviews suggest that longer interventions are better for controlling blood glucose and behavior improvement declines after interventions stop [2]. Our 'optimistic' scenario has demonstrated what may be possible if the TLC Diabetes intervention was offered over a longer period. However, this is an important assumption that should be substantiated with longer-term follow-up data. Other evidence suggests that improved $\mathrm{HbA}_{1 \mathrm{c}}$ levels can be maintained for 36 months following an insulin-based intervention that specifically promotes glycemic control [29]. Similarly, utility values were assumed to be worse for worse glycemic control as supported in literature rather than using the study's data. Varied utility values were tested in the sensitivity analysis and were found to have a strong influence on the base results. However, regardless of the values chosen, the incremental costeffectiveness ratios remained below acceptable levels.

A strength of this research is the use of patient-level data from a randomized controlled trial to compare across strategies, an approach that minimizes the threat of bias for intervention effect and reflects actual healthcare resource use. Participant groups were well-balanced according to baseline socio-demographic and clinical characteristics [4] and few were lost to follow-up. Further, we used Australian data for the relative risk of excess death based on a large study $(n>11,000)$ and utility estimates in Australian patients with diabetes. For resource use, total annual costs for managing diabetes in our participants were very close to that reported in two 
recent Australian studies (approximately $\$ 5000$ (£3284) per year [19, 30]), providing support for the validity of the cost estimates used in the model.

In conclusion, we found that the Australian TLC Diabetes intervention was a low-cost program investment for use by diabetes primary care clinicians to use with individuals with sub-optimally controlled diabetes and may result in medication costsavings for the health system. Moreover, additional intangible benefits arising from the intervention should also be considered when weighing the cost-benefit trade-off with this strategy.

\section{Acknowledgements}

Dr Gordon is funded by a National Health Medical Research Council (NHMRC) Early Career Fellowship (\#496714). This research was presented during an oral presentation at the Gold Coast Health and Medical Research Conference 29-30 Nov 2012 (Gold Coast, Australia) in the Population and Social Health Research Symposium and at the International Health Economics Association World Congress, 7-10 July 2013 (Sydney, Australia). 
Table 1: Key results of mean SF-6D scores and costs ( $£$ 2011)

\begin{tabular}{|c|c|c|c|c|c|}
\hline & $\mathbf{n}$ & Intervention & $\mathbf{n}$ & Usual care & P value \\
\hline \multicolumn{6}{|l|}{ SF-6D scores: mean (SD) } \\
\hline -baseline & 58 & $0.728(0.12)$ & 58 & $0.727(0.14)$ & \multirow{3}{*}{$0.726^{1}$} \\
\hline-6 months & 55 & $0.737(0.12)$ & 55 & $0.727(0.15)$ & \\
\hline-12 months & 55 & $0.736(0.14)$ & 53 & $0.716(0.13)$ & \\
\hline \multicolumn{6}{|c|}{ Mean annual costs ${ }^{2}:(£ 95 \%$ Cls) } \\
\hline - GP \& Specialist visits & & $284(223,345)$ & & $279(221,336)$ & $0.901^{2}$ \\
\hline - Allied health visits & & $114(71,159)$ & & $187(42,332)$ & 0.355 \\
\hline - Hospitalizations & & $2110(746,3462$ & & $2195(342,4047)$ & 0.940 \\
\hline - Medications & & $1076(947,1206)$ & & $1271(1115,1428)$ & 0.052 \\
\hline Total healthcare & & $3585(2162,5008)$ & & $3932(1934,5929)$ & 0.783 \\
\hline
\end{tabular}

1. Calculated using repeated-measures ANOVA

2. Calculated using bootstrap statistics with replacement and the bias-corrected approach with differences tested with the Wald statistic. 
Table 2: Model inputs and sources

\begin{tabular}{lccl}
\hline Description & Base Case & 1-way sensitivity values ${ }^{1}$ and source(s) \\
\hline $\begin{array}{l}\text { Starting age (years) } \\
\begin{array}{c}\text { Discount rate for } \\
\text { costs and/or effects }\end{array}\end{array} 5^{\text {Model duration (years) }}$ & $5 \%$ & 50,70 & Trial population mean age \\
Modian & 5 & $0 \%, 1.5 \%, 3.5 \%$ & Australian standard \\
\hline
\end{tabular}

\begin{tabular}{|c|c|c|}
\hline \multicolumn{3}{|c|}{ 6-monthly transition probabilities between glycae } \\
\hline Usual Care: & $0-6$ mths, & 6-12 mt \\
\hline \multicolumn{3}{|l|}{ Sub-optimal } \\
\hline - Stay & 0.725, & 0.846 \\
\hline - To average & 0.255 & 0.154 \\
\hline - To optimal & 0.020, & 0.000 \\
\hline \multicolumn{3}{|l|}{ Average } \\
\hline - Stay & $\mathrm{n} / \mathrm{a}$, & 0.538 \\
\hline - To optimal & $\mathrm{n} / \mathrm{a}$, & 0.308 \\
\hline - To sub-optimal & $\mathrm{n} / \mathrm{a}$, & 0.154 \\
\hline \multicolumn{3}{|l|}{ Optimal } \\
\hline - Stay & $n / a$ & 0.000 \\
\hline - To average & $\mathrm{n} / \mathrm{a}$, & 0.000 \\
\hline - To sub-optimal & $\mathrm{n} / \mathrm{a}$ & 1.000 \\
\hline
\end{tabular}

TLC intervention:

Sub-optimal

$\begin{array}{lll}\text { - Stay } & 0.574, & 0.931 \\ \text { - To average } & 0.352, & 0.069 \\ \text { - To optimal } & 0.074, & 0.000\end{array}$

Average

$\begin{array}{lll}\text { - Stay } & \mathrm{n} / \mathrm{a}, & 0.400 \\ \text { - To optimal } & \mathrm{n} / \mathrm{a}, & 0.400 \\ \text { - To sub-optimal } & \mathrm{n} / \mathrm{a}, & 0.200\end{array}$

Optimal

- Stay

$\mathrm{n} / \mathrm{a}, \quad 0.250$

- To average

$\mathrm{n} / \mathrm{a}, \quad 0.500$

- To sub-optimal

$\mathrm{n} / \mathrm{a}, \quad 0.250$

\begin{tabular}{lccll}
\hline $\begin{array}{l}\text { HRQoL/Utilities by health state } \\
\text { Sub-optimal }\end{array}$ & 0.727 & $0.617, \quad 0.835$ & $\begin{array}{l}\text { TLC project baseline average, } \\
\text { utilities varied } \pm 15 \%\end{array}$ \\
Average & 0.755 & $0.641, \quad 0.868$ & $\begin{array}{l}\text { Sub-optimal utility }+0.029 \text { [19], } \\
\text { utilities varied } \pm 15 \%\end{array}$ \\
Optimal & 0.783 & $0.666, \quad 0.901$ & Average utility + 0.029 [19], $\pm 15 \%$ \\
\hline $\begin{array}{l}\text { Relative risk of mortality } \\
\text { Background mortality rates }\end{array}$ & Life Tables & & & Australian Bureau of Statistics \\
$\begin{array}{l}\text { Sub-optimal control } \\
\text { Average control }\end{array}$ & 3.5 & $3.0,5.6$ & $\begin{array}{l}\text { Barr et al. 2011 [21], assumption } \\
\text { Optimal control }\end{array}$ \\
\hline
\end{tabular}

Costs (\$AU/ $£$ )

Intervention

Equipment

Running costs

Coordinator costs

Total

6-monthly healthcare costs

GPs and specialist visits

Allied health visits

Hospitalization

Medications - Intervention

Medications - Usual care

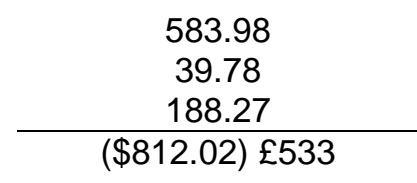

(\$214) £141

(\$118) £77

(\$1635) £1074

(\$823) £540

(\$981) £644
TLC project outcomes $-\mathrm{HbA}_{1 \mathrm{c}}$ values collected within the trial. First 6 month primary outcomes are published [4].
1. Optimistic: transitions for $0-6$ months in 'sub-optimal' are held constant to $5 \mathrm{yrs}$

2. Pessimistic: In the 'average' state, 6-12 months and beyond $=20 \%$ stay in 'average' and $60 \%$ move from 'average' to 'sub-optimal'

3. $0-6$ and $6-12$ month values averaged and held constant to $5 \mathrm{yrs}$

\footnotetext{
1. $\mathrm{HbA}_{1 \mathrm{c}}$ categories are defined as 'sub-optimal' $\geq 58 \mathrm{mmol} / \mathrm{mol}(7.5 \%)$, 'average' $\geq 48-57 \mathrm{mmol} / \mathrm{mol}(6.5$ -
} $7.4 \%$ ) and 'optimal' $<48 \mathrm{mmol} / \mathrm{mol}$ or $(6.5 \%)$. 
Table 3: Results of cost-effectiveness and sensitivity analyses

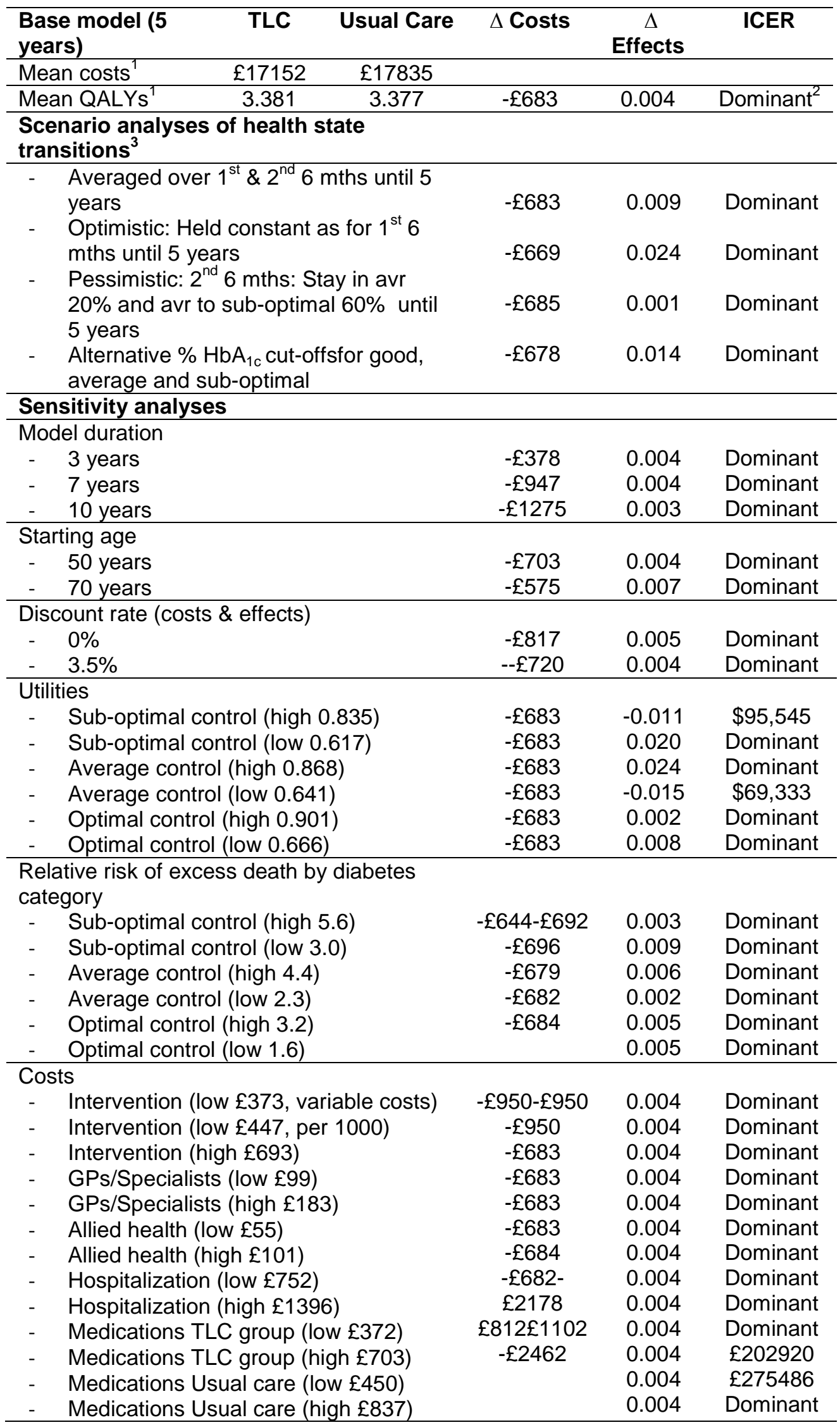

ICER = incremental cost-effectiveness ratio, QALYs = quality-adjusted life years, TLC = telephone-linked care

1. Discounted at $5 \%$ per year to present values. 
2. Dominant or superior means the TLC strategy produced fewer costs and higher QALYs than usual care.

3. $\mathrm{HbA}_{1 \mathrm{c}}$ categories are defined as 'sub-optimal' $\geq 58 \mathrm{mmol} / \mathrm{mol}(7.5 \%)$, 'average' $\geq 48-57 \mathrm{mmol} / \mathrm{mol}(6.5$ $7.4 \%)$ and 'optimal' $<48 \mathrm{mmol} / \mathrm{mol}$ or $(6.5 \%)$.

Figure legends:

Figure 1: Results of probabilistic sensitivity analysis 


\section{References}

[1] Norris SL, Lau J, Smith SJ, Schmid CH, Engelgau MM. Self-management education for adults with type 2 diabetes: a meta-analysis of the effect on glycemic control. Diabetes Care. 2002;25:1159-71. [2] Norris SL, Nichols PJ, Caspersen CJ, Glasgow RE, Engelgau MM, Jack L, et al. Increasing diabetes self-management education in community settings. A systematic review. Am J Prev Med. 2002;22:39-66.

[3] Hu FB. Globalization of diabetes: the role of diet, lifestyle, and genes. Diabetes Care. 2011;34:1249-57.

[4] Williams ED, Bird D, Forbes AW, Russell A, Ash S, Friedman R, et al. Randomised controlled trial of an automated, interactive telephone intervention (TLC Diabetes) to improve type 2 diabetes management: Baseline findings and six-month outcomes. BMC Public Health. 2012;12:602. [5] Farzanfar R, Finkelstein J, Friedman RH. Testing the usability of two automated home-based patient-management systems. J Med Syst. 2004;28:143-53.

[6] Friedman RH. Automated telephone conversations to assess health behavior and deliver behavioral interventions. J Med Syst. 1998;22:95-102.

[7] Friedman RH, Stollerman J, Rozenblyum L, Belfer D, Selim A, Mahoney D, et al. A telecommunications system to manage patients with chronic disease. Stud Health Technol Inform. 1998;52 Pt 2:1330-4.

[8] Adams WG, Fuhlbrigge AL, Miller CW, Panek CG, Gi Y, Loane KC, et al. TLC-Asthma: an integrated information system for patient-centered monitoring, case management, and point-of-care decision support. AMIA Annu Symp Proc. 2003:1-5.

[9] Pinto BM, Friedman R, Marcus BH, Kelley H, Tennstedt S, Gillman MW. Effects of a computerbased, telephone-counseling system on physical activity. Am J Prev Med. 2002;23:113-20.

[10] Ramelson HZ, Friedman RH, Ockene JK. An automated telephone-based smoking cessation education and counseling system. Patient Educ Couns. 1999;36:131-44.

[11] Bird D, Oldenburg B, Cassimatis M, Russell A, Ash S, Courtney MD, et al. Randomised controlled trial of an automated, interactive telephone intervention to improve type 2 diabetes selfmanagement (Telephone-Linked Care Diabetes Project): study protocol. BMC Public Health. 2010;10:599.

[12] Stratton IM, Adler Al, Neil HA, Matthews DR, Manley SE, Cull CA, et al. Association of glycaemia with macrovascular and microvascular complications of type 2 diabetes (UKPDS 35): prospective observational study. BMJ. 2000;321:405-12.

[13] Weinstein MC, O'Brien BJ, Hornberger J, Jackson J, Johannesson M, McCabe C, et al. Principles of Good Practice for Decision Analytic Modeling in Health-Care Evaluation: Report of the ISPOR Task Force on Good Research Practices-Modeling Studies. Value in Health. 2003;6:9-17.

[14] Hirst NG, Whitty JA, Synnott RL, Eley DS, Scuffham PA. Predictors of government subsidized pharmaceutical use in patients with diabetes or cardiovascular disease in a primary care setting: evidence from a prospective randomized trial. J Med Econ. 2011;14:698-704.

[15] Department of Health and Ageing. MBS Online, Medicare Benefits Schedule Update 11/07. p. http://www9.health.gov.au/mbs/search.cfm.

[16] Department of Veteran Affairs. Allied Health Schedule of Fees 2011. p. http://www.dva.gov.au/service providers/Fee schedules/Pages/index.aspx.

[17] Department of Health and Ageing. Pharmaceutical Benefits Scheme (PBS) Online Schedule Canberra: . p. http://www.pbs.gov.au/pbs/home.

[18] Brazier J, Roberts J, Deverill M. The estimation of a preference-based measure of health from the SF-36. Journal of health economics. 2002;21:271-92.

[19] Palmer AJ, Tucker DM. Cost and clinical implications of diabetes prevention in an Australian setting: a long-term modeling analysis. Prim Care Diabetes. 2012;6:109-21.

[20] Barr EL, Zimmet PZ, Welborn TA, Jolley D, Magliano DJ, Dunstan DW, et al. Risk of cardiovascular and all-cause mortality in individuals with diabetes mellitus, impaired fasting glucose, and impaired 
glucose tolerance: the Australian Diabetes, Obesity, and Lifestyle Study (AusDiab). Circulation. 2007;116:151-7.

[21] Barr EL, Boyko EJ, Zimmet PZ, Wolfe R, Tonkin AM, Shaw JE. Continuous relationships between non-diabetic hyperglycaemia and both cardiovascular disease and all-cause mortality: the Australian Diabetes, Obesity, and Lifestyle (AusDiab) study. Diabetologia. 2009;52:415-24.

[22] Briggs A, Gray A. The distribution of health care costs and their statistical analysis for economic evaluation. J Health Serv Res Policy. 1998;3:233-45.

[23] Holtz B, Lauckner C. Diabetes management via mobile phones: a systematic review. Telemed J E Health. 2012;18:175-84.

[24] Barnett TE, Chumbler NR, Vogel WB, Beyth RJ, Ryan P, Figueroa S. The cost-utility of a care coordination/home telehealth programme for veterans with diabetes. J Telemed Telecare. 2007;13:318-21.

[25] Henderson C, Knapp M, Fernandez JL, Beecham J, Hirani SP, Cartwright M, et al. Cost effectiveness of telehealth for patients with long term conditions (Whole Systems Demonstrator telehealth questionnaire study): nested economic evaluation in a pragmatic, cluster randomised controlled trial. BMJ. 2013;346:f1035.

[26] Kesavadev J, Shankar A, Pillai PB, Krishnan G, Jothydev S. Cost-effective use of telemedicine and self-monitoring of blood glucose via Diabetes Tele Management System (DTMS) to achieve target glycosylated hemoglobin values without serious symptomatic hypoglycemia in 1,000 subjects with type 2 diabetes mellitus--a retrospective study. Diabetes Technol Ther. 2012;14:772-6.

[27] Cheung NW, Conn JJ, d'Emden MC, Gunton JE, Jenkins AJ, Ross GP, et al. Position statement of the Australian Diabetes Society: individualisation of glycated haemoglobin targets for adults with diabetes mellitus. Med J Aust. 2009;191:339-44.

[28] Teoh H, Home P, Leiter LA. Should A1C targets be individualized for all people with diabetes? Arguments for and against. Diabetes Care. 2011;34 Suppl 2:S191-6.

[29] Rathmann W, Strassburger K, Tamayo T, Kostev K. Longitudinal change in HbA1c after insulin initiation in primary care patients with type 2 diabetes: a database analysis in UK and Germany. Prim Care Diabetes. 2012;6:47-52.

[30] Lee CM, Colagiuri R, Magliano DJ, Cameron AJ, Shaw J, Zimmet P, et al. The cost of diabetes in adults in Australia. Diabetes Res Clin Pract. 2013. 